\title{
Concentrations of Selected Phthalate Esters in Surface Dust in Omani Houses
}

\author{
Fatma Al Touqi, Hameed Sulaiman, S. P. Sathish Babu, and Hassan Al-Reasi
}

\begin{abstract}
People stay most of the time indoor in humid climatic countries. Since synthetic materials especially plastics occupies our living rooms, indoor-accumulated dust is a health concern. Indoor surface dust samples were collected from living room of households in the city of Muscat, Oman. Samples were analyzed to identify 6 different species of phthalates using gas chromatography/mass spectrometry (GC/MS). Total phthalates concentration ranged from 0.01 to $1864.58 \mu \mathrm{g} / \mathrm{g}$. Di-n-octyl phthalate (DNOP) was the predominant species contributing to more than $80 \%$ of the identified phthalates followed by di-n-butyl phthalate (DnBP) and bis(2-ethylhexyl) phthalate (DEHP). The presence of high concentration of DNOP in surface dust samples probably may reflect the carpet usage in Omani houses. The species of phthalates reported in this study are not comparable to those from studies conducted in other countries.
\end{abstract}

Index Terms-Exposure, muscat, phthalates, surface dust.

\section{INTRODUCTION}

Indoor dust harbors chemicals that have been linked to an increased health risk. Chemicals such phthalates are slowly released from household products, flooring, electrical goods, beauty and cleaning products. Phthalates levels in house dust are reported to be generally more concentrated in the outdoor samples. Phthalates or phthalate esters are a group of chemical compounds used in the production of plastics (as a plasticizers), detergents, adhesives, wood finishes, plumbing pipes, lubricants, medical tubing, medical devices, building materials, and vinyl flooring. Phthalates are hormone-disrupting chemicals that interfere with the production of the male sex hormone, testosterone, which is necessary for proper development and function of the male reproductive organs. The National Academy of Sciences (NAS) [1] concluded that prenatal exposure to seven phthalates caused adverse effects on male reproductive development in animals, causing "phthalate syndrome" which is similar to human "testicular dysgenesis syndrome". As per National Human Activity Pattern Survey [2], People spend more than $87 \%$ of their time in indoor environments, creating a link between indoor environmental quality and their health. In the present study, phthalates levels of indoor surface dust were evaluated in Omani houses. In Oman, the

Manuscript received April 20, 2018; revised July 20, 2018

Fatma Al Touqi is with Wattaya Health Centre, Ministry of Health, Muscat, Oman.

Hameed Sulaiman and Hassan Al-Reasi are with Biology Department, Sultan Qaboos University, Muscat, Oman.

S. P. Sathish Babu is with Central Analytical and Applied Research Unit, Sultan Qaboos University, Muscat, Oman (e-mail: sathishpandi@gmail.com). climate is generally hot and arid, due to which people stay longer time indoors and hence it is important to assess the indoor environment for better health.

\section{MATERIALS AND MethodS}

\section{A. Study Area}

Muscat Governorate is the largest and capital city of Sultanate of Oman. People prefer to spend most of the time indoor since climate is very hot, arid with long summer and the temperature reaches as high as $49^{\circ} \mathrm{C}$. Surface dust samples from Omani dwellings were collected from three main towns of Muscat Governorate namely A'Seeb, Bousher and Muttrah.

\section{B. Method of Collection}

Dust samples were collected from thirty different houses in Muscat within a period of two months (September and October 2014). Vacuum samples from multi-surface objects (35 $\mathrm{cm}$ above the floor level) which includes shelves, cupboards, frames, windowsills, electronic sets and interior material such as wallpaper and the ceiling were collected. The home owners were requested not to vacuum the sampling areas for a period of 1 week before the scheduled sampling.

\section{Questionnaire}

A questionnaire was distributed and collected from each sampled house. The main aim is to find out whether there is any relationship between phthalates concentrations in multi surface dusts to the percentage of plastic materials used in the living space.

\section{Reagents and Standards}

Phthalates standard mixture was purchased from Supelco (40077-U). It includes dimethyl phthalate (DMP), diethyl phthalate (DEP), di-n-butyl phthalate (DnBP), benzyl butyl phthalate (BBP), bis(2-ethylhexyl) phthalate (DEHP), and di-n-octyl phthalate (DNOP). The concentration for each phthalate was $1000 \mu \mathrm{g} / \mathrm{ml}$ in iso-octane. Different concentrations of the standard were prepared in methanol. High-performance liquid chromatography (HPLC) grade hexane and acetone (Sigma) was employed as extraction solvent with hexane: acetone ratio of 1:1.

\section{E. Sample Preparation}

The vacuum dust samples were collected and stored in an amber colored glass bottles. The collected dust samples were air-dried for $24 \mathrm{hrs}$ under a fume hood. Particles other than fine dust like hair, insects, food scrapes, scrape paper and large particles were manually removed by wearing a powder 
free nitrile gloves, face masks, and protective clothing. The dust samples were preserved in the freezer to prevent potential photolysis. Each dust sample was weighed and transferred to a $10 \mathrm{ml}$ glass centrifuge tubes. The extraction solvent $(3 \mathrm{ml})$ was added to each tube containing the sample and vortexed for five minutes to re-suspend the dust particles. The tube was then sonicated for $10 \mathrm{~min}$ and vortexed again to re-suspend the dust particles. The sample were then centrifuged for $5 \mathrm{~min}$ at $1500 \mathrm{rpm}$ and the clear supernatant was transferred to an amber vial. The cycle was repeated two more times for better extraction and all the supernatant fractions were pooled together. The combined extracts were dried under a mild stream of nitrogen and reconstituted to 2 $\mathrm{ml}$ with methanol and analyzed by gas chromatography/mass spectrometry (GC/MS).

\section{F. Analytical Determination}

The GC/MS was operated in electron impact ionization with selective ion monitoring (SIM) mode. The column used for compound separation is DB $5 \mathrm{MS}(30 \mathrm{~m} \times 0.25 \mathrm{~mm} \times$ $0.25 \mu \mathrm{m}$ film thickness) and helium was used as a carrier gas with a constant flow of $0.7 \mathrm{ml} / \mathrm{min}$. The oven temperature ramp program: initial column temperature was $100^{\circ} \mathrm{C}$ held for 2 minutes, then it increased by $10^{\circ} \mathrm{C} /$ minute up to $300{ }^{\circ} \mathrm{C}$ and held for 2 minutes. The inlet temperature was $250^{\circ} \mathrm{C}$, the purge time $0.5 \mathrm{~min}$, and purge flow $75 \mathrm{ml} / \mathrm{min}$ in split-less mode.

\section{RESUlt AND DISCUSSION}

Individual concentrations of six phthalates in surface dust sample from Omani dwellings were assessed. Calibration curve of phthalate standard was linear over a concentration range from $5 \mathrm{pg} / \mu \mathrm{l}$ to $300 \mathrm{pg} / \mu \mathrm{l}$. Correlation coefficient for individual phthalates DMP (0.9999), DEP (0.9959), DnBP (0.9929), BBP (0.9983), DEHP (0.9978), and DNOP (0.9963) were achieved. Concentrations of individual phthalate in surface dust samples are summarized and presented in Table 1. Mean concentration of all six phthalates is represented as pie chart (Fig. 1).

TABLE I: SUMMARY OF CONCENTRATIONS ( $\mu \mathrm{G} / \mathrm{G})$ OF SIX PHTHALATES IN SURFACE DUST

\begin{tabular}{lccccc}
\hline \hline Phthalates & Maximum & Minimum & Mean & Median & $\begin{array}{c}\text { Standard } \\
\text { Deviation }\end{array}$ \\
\hline \hline DMP & 4.99 & 0.01 & 0.61 & 0.38 & 0.99 \\
DEP & 318.18 & 0.01 & 22.16 & 2.03 & 61.38 \\
BBP & 169.12 & 0.01 & 28.02 & 6.27 & 45.86 \\
DEHP & 57.24 & 0.01 & 2.16 & ND & 10.45 \\
& & & & & \\
DnBP & 46.78 & 0.01 & 4.43 & ND & 11.88 \\
DNOP & 1864.58 & 0.01 & 580.59 & 500.83 & 572.18 \\
\hline \hline
\end{tabular}

Percent contribution of individual phthalates in Omani dwellings $(n=30)$ is represented in Fig. 2. The detection frequencies followed the order of DNOP>DEP> $\mathrm{BBP}>\mathrm{DEHP}>\mathrm{DnBP}>\mathrm{DMP}$. The maximum concentration was detected for DNOP in one sample 99.6 percent $(1864$ $\mu \mathrm{g} / \mathrm{g})$ followed by DEP 65 percent $(318 \mu \mathrm{g} / \mathrm{g})$.

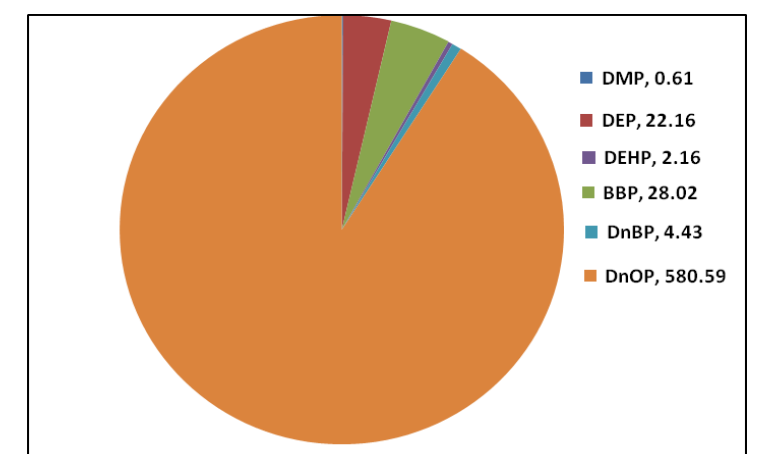

Fig. 1. Pie chart representing the mean concentration of all phthalates.

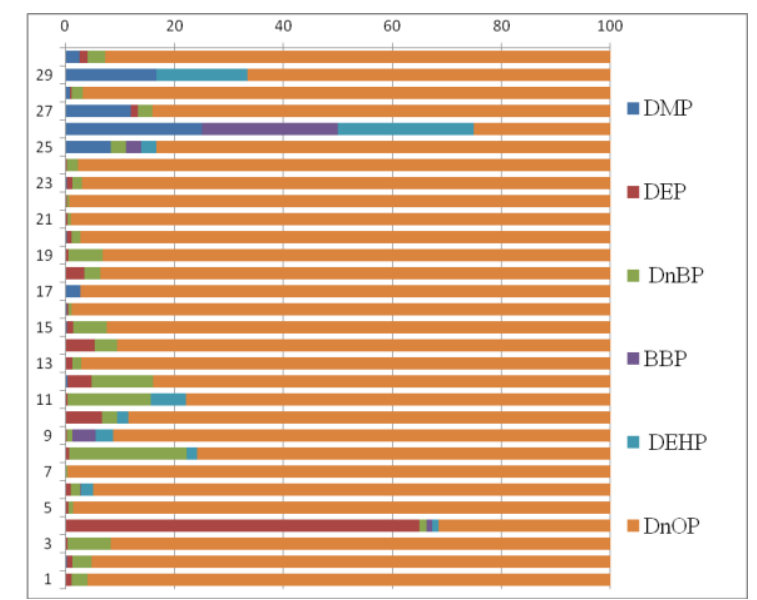

Fig. 2. Percentage contribution of the six phthalates in the thirty house surface dust samples.

Phthalate dust concentrations reported from various countries were tabulated in Table II. Phthalates in dust samples have been studied since 1997 [3]. DEHP was the most abundant phthalate detected in all studies. In present study, DEHP was detected very less compared to DNOP. Of the six phthalates studied, DNOP detected significantly high in most of the houses, in one of the sampled house it was detected as high as $1864 \mu \mathrm{g} / \mathrm{g}$ and (in overall study) with a mean concentration of $580 \mu \mathrm{g} / \mathrm{g}$. DNOP is the phthalate used in carpet back coatings, capacitor fluid and in some cosmetics. The presence of high DNOP concentration in surface dust samples may probably reflect the carpet usage in Omani dwellings. Lower DNOP levels $(41 \mu \mathrm{g} / \mathrm{g})$ were reported in Italy [4] and Bulgaria [5]. In both the studies the concentration of DNOP was comparatively very low relative to levels detected in the present study. And even lower DNOP concentrations were reported in Kuwait study [6]. DMP, DnBP, DEHP are detected lowest in samples. This is same in Kuwait study with the exception of DEHP. Very high levels of DEHP was reported in Kuwait study [6].

Total minimum and maximum concentrations of phthalates detected were 0.01 and $1864.58 \mu \mathrm{g} / \mathrm{g}$, respectively (Table I). Total mean concentration of phthalates found to be $638 \mu \mathrm{g} / \mathrm{g}$, which is comparable with Germany with total mean concentration of phthalate was $564 \mu \mathrm{g} / \mathrm{g}$ [7].

DEP and BBP were the next most detected phthalates. DEP was detected as high as $318 \mu \mathrm{g} / \mathrm{g}$ and BBP $169 \mu \mathrm{g} / \mathrm{g}$. As per WHO [14], DEP was reported as an ingredient in 67 cosmetic formulations, including bath preparations (oils, tablets, and salts), eye shadow, toilet waters, perfumes and other fragrance preparations, hair sprays, wave sets, nail polish and enamel removers, nail extenders, bath soaps, 
detergents, aftershave lotions, and skin care preparations. repellents. DEP is also used in insecticide sprays and mosquito

TABLE II: CONCENTRATION $(\mu \mathrm{G} / \mathrm{G})$ OF SiX PHTHALATES MEASURED IN THIS STUdy AND OTHER STUDIES

\begin{tabular}{|c|c|c|c|c|c|c|c|}
\hline Country & $\mathrm{n}$ & DMP & DEP & $\mathrm{BBP}$ & DEHP & DNBP & DNOP \\
\hline $\begin{array}{l}\text { Norway } \\
\text { Øie et al. (1997) [3] }\end{array}$ & 38 & - & 10 & 110 & 640 & 100 & - \\
\hline $\begin{array}{l}\text { Denmark } \\
\text { Clausen et al. (2003) [8] }\end{array}$ & 23 & - & - & - & 3214 & - & - \\
\hline $\begin{array}{l}\text { USA } \\
\text { Hwang et al. (2008) [9] } \\
\text { Germany }\end{array}$ & 11 & - & - & - & 386 & - & - \\
\hline Abb et al. (2009) [10] & 30 & - & - & 15.2 & 604 & 87.4 & - \\
\hline $\begin{array}{l}\text { Japan } \\
\text { Kanazawa et al. (2010) [11] }\end{array}$ & 41 & - & 0.33 & 4.2 & 880 & 19.8 & - \\
\hline $\begin{array}{l}\text { Germany } \\
\text { Langer et al. (2010) [12] }\end{array}$ & 30 & 2 & 6 & 29 & 659 & 47 & - \\
\hline $\begin{array}{l}\text { Sweden } \\
\text { Caroline. (2011) [13] }\end{array}$ & 10 & 15 & 1300 & 21 & 200 & 850 & - \\
\hline $\begin{array}{l}\text { Kuwait } \\
\text { Gevao et al .(2012) [6] }\end{array}$ & 21 & 0.02 & 1.8 & 7.9 & 2256 & 45 & 12.9 \\
\hline $\begin{array}{l}\text { Oman } \\
\text { This study }\end{array}$ & 30 & 0.38 & 2.03 & 6.27 & 2.16 & 4.43 & 580.59 \\
\hline
\end{tabular}

BBP is added to polyvinyl chloride as a plasticizer. It helps the polymers from becoming entangled will increase the flexibility of the PVC, making it more suitable for a number of applications, like vinyl fabrics, raincoats etc. The emission of BBP from vinyl floorings with the influence of temperature was reported elsewhere [15]. A study in Sweden found that children are more likely to develop asthma when they lived in homes with vinyl floorings [16].

In this study, plastic materials in the sampled houses were compared with that of detected phthalates. It was found that there is no correlation between the phthalate concentration and the percentage of plastic materials used in the sampled houses. In Omani houses, mainly living room has maximum carpet cover areas.

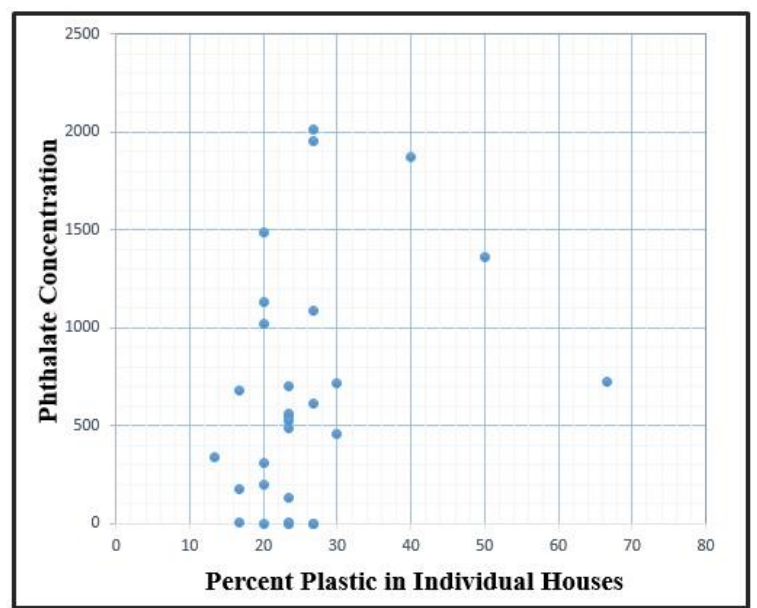

Fig. 3. Total phthalate concentration versus percentage of plastic materials in the individual houses.

The amount of phthalates in house dust tends to increase with increasing carpet cover has been reported by Abb et al. (2009) [10]. The correlation between the phthalate concentration and the percentage of carpet cover area, age of the carpet and temperature of the living room needs to be investigated. However, it was difficult to precisely identify the sources of phthalates in indoor environment.

\section{CONCLUSION}

Overall relative abundance of studied phthalates in Omani houses were in the order of DNOP $>$ DnBP $>$ DEHP $>$ BBP> DEP > DMP. DNOP was found to be very high when compared to other studies. The higher level of DNOP in house dusts needs to be investigated to identify the exact source of this compound. In general, many studies have concluded that the highest concentration of phthalates was found in poorly ventilated indoor environment. Houses in Oman are having this typical indoor setting due to air conditioning necessity that limit the air exchange (fresh air) in the houses. It is necessary to innovate for building houses with structural modifications that enhance dispersing indoor pollutants released in the houses.

\section{ACKNOWLEDGMENT}

The authors like to thank all the heads of the households for cooperating with us to collect samples.

\section{REFERENCES}

[1] National Academy of Science, "Phthalates and cumulative risk assessment," The National Academic Press, 2008.

[2] N. E. Klepeis, W. C. Nelson, W. R. Ott, J. P. Robinson, A. M. Tsang, P. Switzer, J. V. Behar, S. C. Hern, and W. H. Engelmann, "The National Human Activity Pattern Survey (NHAPS): A resource for assessing exposure to environmental pollutants," Journal of Exposure Analysis and Epidemiology, vol. 11, pp. 231-252, 2001.

[3] L. Oie, L. G. Hersoug, and J. O. Madsen, "Residential exposure to plasticizers and its possible role in the pathogenesis of asthma," Environ Health Perspectives, vol. 105, pp. 972-978, 1997.

[4] S. Orecchio, R. Indelicato, and S. Barreca, "The distribution of phthalate esters in indoor dust of Palermo (Italy)," Environ Geochem Health, vol. 35, pp. 613-624, 2013.

[5] B. Kolarik, C. G. Bornehag, K. Naydenov, J. Sundell, P. Stavova, and O.F. Nielsen, "The concentrations of phthalates in settled dust in Bulgarian homes in relation to building characteristic and cleaning habits in the family," Atmospheric Environ, vol. 42, pp. 8553-8559, 2008.

[6] B. Gevao, A. N. Al-Ghadban, M. Bahloul, S. Uddin, and J. Zafar, "Phthalates in indoor dust in Kuwait: implications for non-dietary human exposure," Inter J of Indoor Environ and Health, vol. 23, 2012. 
[7] A. Pohner, S. Simrock, J. Thumulla, S. Weber, and T. Wirkner, "Hinter grundbelstung des hausstaubes von privathauhalten mit mittel und schwerfluchtigen organischen schadstoffen," Umwelt Gesundheit, vol. 2, pp. 1-64, 1997.

[8] G. Clausen, A. Host, J. Toftum, G. Beko, C.J. Weschler, M. Callesen, S Buhl, M. Ladegaard, S. Langer, B. Andersen, J. Sundell, C. G. Bornehag, and T. Sigsgaard, "Indoor Environment in Children's Health (IECH) - an ongoing epidemiological investigation on the association between indoor environmental factors in homes and kindergartens and children's health and wellbeing," in Proc. the $9^{\text {th }}$ International Healthy Building Conference, 2009.

[9] H. M. Hwang, E. K. Park, T. M. Young, and B. D. Hammock, "Occurrence of endocrine disrupting chemicals in indoor dust," Sci of the Total Environ, vol. 404, pp. 26-35, 2008.

[10] M. Abb, T. Heinrich, E. Sorkau, and W. Lorenz, "Phthalates in house dust," Enviro Inter, vol. 35, pp. 965-970, 2009.

[11] A. Kanazawa, I. Saito, A. Araki, M. Takeda, M. Ma, and Y. Saijo, "Association between indoor exposure to semi-volatile organic compounds and building related symptoms among the occupants of residential dwellings," Indoor Air, vol. 20, pp. 72-84, 2010.

[12] S. Langer, C. J. Weschler, A. Fischer, G. Beko, J. Toftum, and G. Clausen, "Phthalate and PAH concentrations in dust collected from Danish homes and daycare centers," Atmospheric Environ, vol. 44, pp. 2294-2301, 2010.

[13] B. Caroline, "Organophosphates and phthalates in air and dust from indoor environments - Method development and applied measurements," Ph.D. dissertation, Dept. Anal. Chem. Stockholm Univ., Sweden, 2011.
[14] WHO, Concise International Chemical Assessment Document 52 Diethyl Phthalate, 2003.

[15] Y. Liang and Y. Xu, "Emission of phthalates and phthalate alternatives from vinyl flooring and crib mattress covers: The influence of temperature," Environmental Science and Technology, vol. 48, pp. 14228-14237, 2014

[16] H. Shu, B. A. Jonsson, M. Larsson, E. Nanberg, and C. G. Bornehag, "PVC flooring at home and development of asthma among young children in Sweden, a 10-year follow-up," Indoor Air, vol. 24, pp. $227-235,2014$

Fatma Al Touqi is a post graduate in Environmental science working as a public health practitioner at Ministry of Health in Oman.

Hameed Sulaiman and Hassan Al-Reasi are faculties in the Biology Department, Sultan Qaboos University, Muscat, Oman. Both they are currently involved in teaching and research in the Biology Department at Sultan Qaboos University, Oman.

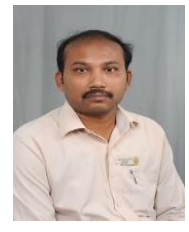

S. P. Sathish Babu was born in Tamilnadu, India on May 5, 1979. He received his BSc and MSc in microbiology from University of Madras and MPhil in biotechnology from Bharathidasan University, Trichy, Tamilnadu. $\mathrm{He}$ is currently working as a researcher at Central Analytical and Applied Research Unit, College of Science, Sultan Qaboos University, Muscat, Sultanate of Oman. 